\title{
UM ESTUDO SOBRE AS PARTES INTERESSADAS DO PROGRAMA MERCADO PÚBLICO REGIONAL (MPR) NO ÂMBITO DO CONSÓRCIO INTERMUNICIPAL DE DESENVOLVIMENTO ECONÔMICO, SOCIAL E MEIO AMBIENTE - CIDEMA COM BASE NO PMI ${ }^{R}$
}

\author{
L.L. Koch ${ }^{1 *}$; R. Barichello ${ }^{1}$; C. A. Jacoski ${ }^{1}$
}

1 Universidade Comunitária da Região de Chapecó, 89809-000, Chapecó - SC, Brasil

*leani@unochapeco.edu.br

\section{RESUMO}

A presente pesquisa tem como objetivo principal analisar o gerenciamento do Programa Mercado Público Regional (MPR) de Chapecó, administrado pelo Consórcio Intermunicipal de Desenvolvimento Econômico, Social e Meio Ambiente - CIDEMA a partir das partes interessadas. Em relação aos procedimentos metodológicos, a pesquisa classifica-se como descritiva. Para coleta de dados, formulou-se um questionário estruturado, aplicado aos Secretários da Agricultura dos municípios que tem espaço para comercializar produtos no MPR e, entrevista semiestruturada com o administrador do MPR e dois Secretários para contribuir nas análises, obteve-se um retorno de $85 \%$ dos questionários. Os resultados mostram que os municípios pesquisados tem sua base econômica alicerçada na agricultura familiar. A gestão do MPR é compartilhada entre CIDEMA e municípios, porém, não possuem unificação quanto ao processo, geralmente cada município utiliza metodologias próprias para gerir o Programa. A pesquisa revelou lacunas quanto ao envolvimento das partes interessadas ao longo do ciclo de vida do Programa, compreende, desde a capacitação dos responsáveis, ausência de análise ambiental considerando os diferenciais e potenciais de cada município, falta de logística integrada e, clareza das atribuições dos envolvidos. Observou-se também, que o Programa beneficia famílias em aspectos sociais, melhorando a qualidade de vida.

\section{A STUDY ABOUT THE INTERESTED PARTS OF THE PUBLIC REGIONAL MARKET PROGRAMME (MPR) IN THE INTERMUNICIPAL CONSORTIUM FOR ECONOMIC, SOCIAL AND ENVIRONMENT DEVELOPMENT- CIDEMA BASED ON PMI ${ }^{\mathrm{R}}$.}

\begin{abstract}
The present study aimed to analyze the management of the Public Regional Market Programme (MPR), in Chapecó, administered by the Intermunicipal Consortium of Economic, Social and Environment Developments CIDEMA from the perception of interested parts that take part in the program. Regarding the methodological procedures, the research is classified as descriptive. To collect the data, a structured questionnaire was made and applied to MPR manager and two Agriculture Secretaries to contribute in the analysis, there was a return of $85 \%$ of the questionnaires. The program council and semistructured interviews were made with the MPR manager and with two responsibles for the program in the municipality. The results showed that the surveyed
\end{abstract}

municipalities have their economic base rooted in family farming. MPR management is shared between CIDEMA and municipalities, however, they don't have unity in the process conduction, each municipality usually uses own methodologies to manage the program. The survey revealed gaps in the involvement of the interested parts throughout the program lifecycle, extending from the training of those responsible, the absence of environmental analysis considering the advantages and potential of each municipality, the lack of integrated logistics and the clarity in the attributions of those involved. It was also observed that the program benefits families in social aspects, improving the life quality.

KEYWORDS: projects management, interested parts, public regional market, management. 


\section{INTRODUÇÃO}

O panorama mundial vivencia incertezas e exige adequações por parte das organizações, sejam públicas ou privadas. O processo de Gestão de Projetos aponta como uma ferramenta para diferenciar as empresas e órgão públicos que buscam atender as exigências do mercado e as demandas coletivas por produtos/serviços de qualidade. Nessa perspectiva, destaca-se a importância dos projetos nas organizações como meio de promover mudanças (KEELING, 2002). O aumento da competitividade e a disputa diária pelo mercado deixam as organizações mais vulneráveis diante de uma economia instável e das tecnologias investidas no desenvolvimento de projetos das mais diferentes ordens. Nesse cenário o gerenciamento de projetos tem se tornado uma forma efetiva para coadunar esforços, aplicar conhecimentos, habilidades, ferramentas e técnicas as atividades do projeto com o objetivo de atender sua demanda (PMI, 2014).

As corporações estão expostas às mudanças oriundas do mercado globalizado, novidades tecnológicas, posicionamento mercadológico, variações sociopolíticas e, todas impactam diretamente nas organizações. Dentre as organizações, sobressaem as empresas precursoras da inovação e emprego do empreendedorismo na gestão, enquanto outras somente acompanham as mudanças, e também há as que são estáticas, paradas no tempo e espaço (VALLE et al., 2014). É nesse contexto de mudanças que se percebe a necessidade de repensar as práticas organizacionais relacionadas ao gerenciamento de projetos, buscando responder as exigências do mercado que demanda produtos com um ciclo de vida cada vez menor e com novas tecnologias empregadas. Nessa conjuntura, se faz necessário considerar diversos fatores, porém um fator que se evidência é o gerenciamento das partes interessadas no projeto. No que tange o gerenciamento das partes interessadas, Noro (2012), afirma existir muitas lacunas, uma vez que essa vertente é pouco explorada e apreciada, também indica uma frequência tímida ou nula na composição dos princípios de gestão para compor um projeto

Considerando esses aspectos, PMI (2014), traz na sua quinta edição, a décima área do conhecimento em Gestão de Projetos, o Gerenciamento das Partes Interessadas, que consiste no gerenciamento dos processos necessários para identificar pessoas, grupos ou organizações que influenciam ou são influenciadas no projeto.

Nessa lógica o Consórcio Intermunicipal de Desenvolvimento Econômico, Social e Meio Ambiente (CIDEMA) aufere destaque ao empregar esforços conjuntos para gerenciar o Programa Mercado Público Regional (MPR) com os municípios parceiros, além de fomentar o fortalecimento econômico e produtivo de municípios de pequeno e médio porte. Através da associação fortalece a microrregião com as parcerias entre municípios, agricultura familiar e consumidor. A mobilização que advém dos programas e projetos de forma integrada entre o CIDEMA e municípios promovem potencialidades apoiadoras, identificam os problemas críticos e formulam estratégias apropriadas para o seu enfrentamento. Tendo como referência o tema Gestão de Projetos relacionado ao gerenciamento das partes interessadas do projeto, propõe-se nesse estudo responder a seguinte problemática: Como ocorre o gerenciamento do Programa Mercado Público Regional (MPR) de Chapecó na visão das partes interessadas (municípios)? Buscando responder a problemática apresentada, estabelece-se como objetivo geral deste estudo analisar o gerenciamento do Programa MPR de Chapecó a partir da percepção das partes interessadas (municípios e CIDEMA). Com a finalidade de atender o objetivo geral, se propôs como objetivos específicos deste trabalho: Mapear as partes interessadas (municípios) atuantes no Programa MPR; Investigar a gestão e negociação de conflitos das partes interessadas (municípios) do Programa; Identificar o grau de responsabilidades e influências das partes interessadas (municípios e CIDEMA) na gestão do Programa. 
A estrutura da pesquisa primeiramente introduz o tema pesquisado, apresenta a problemática de pesquisa e os objetivos geral e específico, no segundo momento apresenta-se a revisão de literatura, estrutura para a pesquisa. No terceiro momento a metodologia de pesquisa, que consiste numa abordagem descritiva quali-quanti, utilizou-se entrevista e questionário estruturado para coleta de dados, teve como população alvo da pesquisa as partes interessadas, os sete municípios e o administrador do Programa MPR, em seguida apresenta-se a análise e discussão dos resultados coletados. Por fim, apresentam-se as conclusões e recomendações de trabalhos futuros.

\subsection{Gestão de Projetos e as Partes Interessadas}

A gestão de projetos vem angariando adeptos em diferentes contextos organizacionais na busca pela sustentabilidade, porém de tamanha notoriedade e sofisticação, que exige uma postura organizacional que remete a análise do processo até então empregado de forma mecânica e rotineira. Buscam-se meios competitivos e sustentáveis na elaboração e desenvolvimento dos projetos, bem como o envolvimento das partes interessadas. De acordo com o Project Management Institute (PMI), a maior associação mundial de gerenciamento de projetos, define gerenciamento de projetos como "[...] a aplicação de conhecimentos, habilidades, ferramentas e técnicas às atividades de projeto a fim de atender aos seus requisitos" (PMI, 2014, p.05). Vargas (2009, p. 7) corrobora ao abordar que o "projeto é um empreendimento não repetitivo, caracterizado por uma sequência clara e lógica de eventos, com início, meio e fim, que se destina a atingir um objetivo claro e definido, [...]" com "[...] parâmetros predefinidos de tempo, custo, recursos envolvidos e qualidade". Para PMI (2014, p. 417), "projeto é um esforço temporário empreendido para criar um produto, serviço ou resultado único". Uma característica importante dos projetos é a elaboração progressiva, que permite o seu desenvolvimento em etapas incrementais, contudo, os projetos são únicos e temporários, envolvem recursos materiais e humanos. O resultado de um projeto poder ser tangível ou intangível (KEELLING; BRANCO, 2014; PMI, 2014; VALLE et al., 2014; VARGAS, 2009).

Para o Governo Federal projeto é um "instrumento de programação para alcançar o objetivo de um programa, envolvendo um conjunto de operações, limitadas no tempo, das quais resulta um produto que concorre para a expansão ou aperfeiçoamento da ação do Governo" (Manual de Elaboração do PPA 2012-2015, p. 44). Observa-se a importância dos projetos para uma Administração Pública mais efetiva, possibilita coordenar esforços para a expansão e melhora das ações do Governo na prestação de serviços/produtos para a população. Muitas organizações, instituições de pesquisa e em especial a Ádministração Pública, nas esferas, federal, estadual e municipal administram programas nos quais ocorrem o agrupamento de projetos afins, buscando-se alcançar objetivos mais amplos em determinado campo. Alguns programas se apresentam como uma série de projetos agrupados com o intuito de harmonizar seus componentes a fim de obter benefícios específicos (BRASIL, 2006; KEELLING, 2002; PMI, 2014). Os programas devem considerar as políticas internas, e seu desempenho deve ser mensurado por indicadores (BRASIL, 2006).

Diante das constantes exigências mercadológicas globais, no contexto do gerenciamento de projetos, PMI (2014) traz na $5^{a}$ edição do Guia PMBOK, a décima área do conhecimento, denominada como Gerenciamento das Partes Interessadas. Trentim (2013) assegura que os projetos atuais, dadas suas incertezas e complexidade, além da volatilidade do ambiente, exigem novas abordagens, motivo pelo qual o gerenciamento das partes interessadas equivale a uma relação de troca. As partes interessadas podem ser compreendidas e caracterizadas como, indivíduo, grupo ou organização que pode afetar, ser afetada por uma decisão, atividade ou resultado de um projeto. Além de compor um processo que compreende diversos processos menores, como conhecer cada um de seus interesses, de sua habilidade de influenciar e de sua posição, sendo ela favorável ou 
desfavorável ao projeto e, além de definir estratégias para lidar com cada uma (MAXIMIANO, 2010; PMI, 2014).

Trentim (2013) e PMI (2014) acrescentam que ao lidarmos com as partes interessadas na gestão de projetos, não lidamos apenas com grande número de partes interessadas, mas também com suas expectativas, aspectos políticos, decisões técnicas, gerenciais e estratégicas, entre outros fatores que possam estar ligadas diretamente ou indiretamente a organização. Acrescentam ainda que se faz necessário identificar e envolver as partes interessadas no início dos projetos, revelando o que eles pretendem e, estabelecendo meios de administrar, monitorar e controlar o seu envolvimento em todo o projeto, pois a relação entre as partes interessadas no que tange ao projeto é desenvolvida em diversos níveis de responsabilidade e autoridade, contudo, pode variar ao longo do ciclo de vida do projeto. Destacam também que a identificação das partes interessadas já é algo difícil, mais complicado ainda é definir suas prioridades e necessidades em relação ao projeto, já que essas expectativas não são estáticas.

Dentre fatores de destaque para o envolvimento das partes interessadas, cita-se o gerente de projetos (KEELLING, 2002; PMI, 2014; TRENTIM, 2013; VALLE et al., 2014). Compete ao gerente de projeto administrar as expectativas das partes interessadas, equilibrar esses interesses e garantir que a equipe do projeto interaja com as partes interessadas de modo profissional e cooperativo. A sequência atribuída ao processo na concepção de PMI (2014) contempla: identificar as partes interessadas; planejar o gerenciamento das partes interessadas, gerenciar o engajamento das partes interessadas e, controlar o engajamento das partes interessadas. Esses processos interagem entre si e as demais áreas do conhecimento, além da influência que constituem ao longo projeto.

Identificar as partes interessadas permite ao gerente de projetos adotar a estratégia mais assertiva para administrar os stakholders. Possibilita o direcionamento mais adequado para satisfazer esta área do conhecimento, principalmente, considerando a influência, positiva ou negativa em relação ao sucesso do projeto (PMI, 2014). Essa classificação está intrinsecamente relacionada com as ações das pessoas que estão envolvidas de forma atuante ou como afetadas. Para PMI (2014) a análise das partes interessadas segue algumas etapas, sendo elas: identificar todas as partes potenciais do projeto, bem como elementos pertinentes, como papéis, setores, interesses, conhecimentos, perspectivas e graus de influência; identificar o impacto ou ajuda possível das partes, classificá-los para estruturar a estratégia de trabalho, isso facilita a gestão, direciona esforços e investimentos nas partes com maior impacto no projeto, considerando as expectativas; aferir a reação ou resposta das partes principais nas mais diferentes posições, buscando influenciá-los a maximizar o apoio e mitigar os momentos negativos em potencial.

Entre os diferentes modelos de classificação para analisar as partes interessadas quanto o interesse e o poder. PMI (2014) contempla: grau de poder/interesse - relaciona as partes interessadas com base no estado de autoridade (poder) e o de preocupação (interesse); grau de poder/influência - relaciona as partes interessadas quanto ao estado de autoridade (poder) e o de engajamento ativo (influência); grau de influência/impacto - relaciona as partes interessadas com base no estado de engajamento ativo (influência) e sua capacidade de motivar mudanças quanto ao planejamento ou execução do programa (impacto); e modelo de relevância - caracteriza as partes interessadas quanto sua imposição de pretensões, nas vontades imediatas e na validade (legal).

Planejar o gerenciamento das partes interessadas para PMI (2014) é a técnica de aprimorar as estratégias, envolver de maneira eficaz ao longo do ciclo de vida, atender as necessidades, interesses e o potencial do projeto. O principal objetivo é a interação e o apoio das partes interessadas, permite também ao gerente de projetos desenvolver métodos para engajar as partes interessadas, satisfazendo suas necessidades dentro dos regulamentos do projeto. Metodologias que 
podem ser empregadas através de reuniões com especialistas e a equipe do projeto que permite definir o engajamento e o nível de envolvimento das partes interessadas. Outra ferramenta é a utilização das técnicas analíticas, o nível de engajamento atual deve ser confrontado com o planejado, permitindo-se identificar lacunas entre o atual e o esperado visando o sucesso do projeto em todas as etapas. O nível de engajamento das partes interessadas no entendimento de PMI (2014) pode ser categorizado, como: o desinformado, o resistente, o neutro, dá apoio, e lidera.

Gerenciar o engajamento das partes interessadas envolve o processo de comunicação que é o elo entre a gerência e as partes interessadas, visa atender as expectativas e necessidades na medida em que surgem ao longo do ciclo de vida do projeto. Busca identificar pontos críticos com antecedência, solucionar os conflitos e potencializar o sucesso. Com as atualizações nos ativos de processos organizacionais, como: notificações das partes interessadas; relatórios de projeto; apresentações do projeto; registros do projeto; feedback das partes interessadas e a documentação de lições aprendidas. Essa fase permite o registro e a comunicação das principais causas de eventos, tanto positivos quanto negativos, fomentando o banco de dados do projeto para que possam ser usados em futuros projetos organizacionais (PMI (2014).

Controlar o engajamento das partes interessadas remete a um processo de monitoramento e, nesses termos, PMI (2014, p.409) descreve que "controlar o engajamento das partes interessadas é o processo de monitorar os relacionamentos das partes interessadas no projeto em geral, e ajustar as estratégias e planos para o engajamento das mesmas". Um dos principais benefícios é o aumento significativo da eficiência e eficácia das atividades na medida em que o projeto se desenvolve e muda o ambiente. O grau de engajamento das partes interessadas carece de controle contínuo. Com o controle, o monitoramento a organização fomenta os dados e fortalece a documentação de lições aprendidas, o que por sua vez, promove a retroalimentação para o processo de gerenciamento de projetos futuros.

\subsection{Projeto aplicado à área pública - Programa Mercado Público Regional (MPR)}

Em empreendimentos públicos alguns fatores precisam ser identificados e considerados tanto na etapa de idealização bem como na implantação de projetos, formação de equipes e execução de projetos. As esferas de governo federal, estadual e municipal são constituídas por inúmeros órgãos, segmentos e pessoas (além de funcionários públicos) e esses atores, nem sempre compartilham os mesmos objetivos e, menos ainda, concordam na forma de gestão para atingi-los (CARVALHO, 2012).

As principais diferenças concentram-se em: aspectos sociais dos projetos governamentais; obrigatoriedade de previsão orçamentária para a execução do projeto e previsto em Lei Orçamentária Anual (LOA); obediência a Lei de licitações, mais especificamente a Lei 8.666/93 que regula a contratação dos produtos e serviços na área pública; as normatizações que delongam os processos e, as execuções dos projetos; o controle por parte de diferentes órgãos em diversas esferas de governo; a publicidade (prestação de contas) à sociedade por força da transparência na gestão pública (CARVALHO, 2012). Observa-se que no setor público, o principal objetivo não é o lucro, e sim a prestação de serviços de qualidade que atendam as necessidades da sociedade. Sociedade que, via de regra, é a patrocinadora dos possíveis benefícios a ela aplicada. Porém, existem dificuldades para o alcance desses objetivos, de acordo com Silva et al.(2013), é mais corriqueiro sobrepor os objetivos políticos em detrimento dos interesses da sociedade.

O Programa MPR foi idealizado com recursos de 17 municípios da associação dos municípios do oeste de Santa Catarina (AMOSC) e do Governo Federal. Iniciou suas atividades em 2007, com sede no município de Chapecó Santa Catarina, polo consumidor com mais de 200 mil habitantes, motivo esse que levou a centralização do MPR, buscando potencializar a 
comercialização dos produtos da agricultura familiar de toda a região da AMOSC, eliminando os atravessadores entre produtor e consumidor final, além de agregar valor ao produto e elevar a renda do produtor rural.

O MPR é administrado pelo Consórcio Intermunicipal de Desenvolvimento Econômico, Social e Meio Ambiente (CIDEMA). Ao iniciar suas atividades em 2007, contava com 10 municípios associados (Caxambu do Sul, Chapecó, Cordilheira Alta, Coronel Freitas, Guatambu, Nova Itaberaba, Quilombo, Santiago do Sul, São Carlos e União do Oeste). A maior finalidade do MPR é promover os produtos da agricultura familiar dos municípios associados e, contribuir com o desenvolvimento integrado de toda a região, com um ambiente inovador para vendas no varejo e showroom dos produtos da agricultura familiar.

Os municípios interessados em comercializar os produtos manifestam interesse ao CIDEMA, que no ato elabora contrato de rateio anual (valor pago mensalmente ao CIDEMA) com o município, que assim, passará a ter direito a um boxe (espaço para comercialização), luz, água e demais encargos administrativos para comercialização dos produtos no MPR. Em relação ao abastecimento e a comercialização dos produtos, a responsabilidade é de cada município.

O MPR além de comercializar produtos oriundos da agricultura familiar dos municípios associados ao CIDEMA possui um amplo espaço para realização de eventos, com auditório, restaurante e estacionamento, o que fomenta a concepção inicial do MPR, um tripé com: comercialização, gastronomia e cultura. Contudo, atualmente o Programa MPR conta com 7 (sete) municípios associados, e destes somente 5 (cinco) municípios estão comercializando produtos da agricultura familiar.

\section{MATERIAIS E MÉTODOS}

No que tange aos procedimentos metodológicos, a presente pesquisa classifica-se como aplicada. A pesquisa aplicada tem na motivação básica a resolução de problemas concretos, além da possibilidade de contribuir teoricamente com novos eventos para a compreensão teórica de diferentes campos do conhecimento (FERRARI, 1982). Quanto à natureza dos dados, a pesquisa assume um caráter qualitativo e quantitativo. Na compreensão de Demo (2000, p. 152), "a pesquisa qualitativa quer fazer jus à complexidade da realidade, curvando-se diante dela, não o contrário, como ocorre com a ditadura do método ou demissão teórica que imagina dados evidentes." Já no método quantitativo, busca-se descobrir e classificar a relação entre variáveis, bem como, a relação de causalidade entre fenômenos (RICHARDSON, et al., 2011). No que se refere aos objetivos, a presente pesquisa caracteriza-se como exploratória e descritiva, pois "têm por objetivo proporcionar maior familiaridade com o problema, com vistas a torná-lo mais explícito ou a construir hipóteses. [...] que possibilite a consideração dos mais variados aspectos relativos ao fato estudado" (GIL, 2002, p.41). Vergara (2000, p.47), afirma que a pesquisa descritiva "expõe características de determinada população ou determinado fenômeno. Pode também estabelecer correlações entre variáveis e definir sua natureza. Não tem compromisso de explicar os fenômenos que descreve, embora sirva de base para tal explicação".

Realizou-se um estudo bibliográfico que serviu de arcabouço para a elaboração do instrumento de coleta de dados, com o propósito de atingir os objetivos da pesquisa. Elaborou-se um questionário estruturado, dividido em quatro partes: a primeira buscando levantar dados para caracterizar as partes interessadas do Programa MPR; a segunda visando informações sobre a gestão do Programa; a terceira relacionando o grau de responsabilidade e influências das partes interessadas na gestão; e a quarta relacionando/identificando o município com o Programa. 
O questionário contemplou questões fechadas de múltipla escolha, utilizando a escala Likert definida com 2 níveis de discordância e e 2 níveis de concordância, e 1 opção de neutralidade, (1discordo totalmente. 2 - discordo parcialmente. 3 - indiferente. 4 - concordo parcialmente, e 5 concordo totalmente). Também foram realizadas entrevistas semi-estruturadas com o administrador do Programa e dois Secretários da Agricultura, buscando aprofundar detalhes da gestão e funcionamento do Programa.

A população da pesquisa foi composta pelos 7 (sete) municípios que tem espaço para comercialização de produtos no MPR, situado no município de Chapecó - Santa Catarina e, o administrador do Programa por parte do CIDEMA. O instrumento de coleta foi pré-testado para validação em um município participante e, posteriormente, aplicado através de um formulário encaminhado via e-mail a cada Secretário da Agricultura responsável pelo Programa em seu município.

A amostra contou com 6 (seis) municípios respondentes, contemplando $85 \%$ da população alvo, o que corresponde uma representação significativa para a pesquisa. Apenas 1 (um) município se absteve em responder o questionário.

Os dados foram tabulados com auxilio de software estatístico, com a média de respostas por pergunta das questões analisadas. As análises dos questionários foram sob a ótica quantitativa e qualitativa, e as entrevistas auxiliaram na compreensão dos resultados. $\mathrm{Na}$ análise dos dados, os municípios não serão identificados, e os dados expostos de forma global.

\section{RESULTADOS E DISCUSSÃO}

Esta etapa da pesquisa apresenta a descrição e a análise dos dados coletados, respondendo aos objetivos do estudo. Aborda-se as Características dos municípios pesquisados, a Gestão do Programa MPR, Responsabilidades e influências na gestão do Programam MPR e, a Identificação do município com Programam MPR.

\subsection{Municípios pesquisados - características}

Os municípios analisados estão localizados na região oeste de Santa Catarina, tem sua base econômica essencialmente na agricultura familiar, com sua população variando de, aproximadamente, 5000 a 15000 habitantes, com maior concentração em até 5000 habitantes em $67 \%$ dos municípios. A emancipação de $50 \%$ dos municípios varia entre 20 e 30 anos, e o restante tem mais de 50 anos de emancipação. Buscando analisar as características internas dos municípios pesquisados quanto ao Programa MPR, verificou-se aspectos em relação à participação nas atividades de comercialização no MPR, constatou-se que 50\% dos municípios analisados estão com suas atividades desde a abertura do MPR, de forma ininterrupta, já os outros 50\%, oscilam, com comercialização ativa em períodos sazonais, ou seja, abrem para comercialização quando tem demanda de mercadorias e fecham, quando ocorre escassez de produtos ou por questões administrativas internas a organização. Quanto aos indicadores da escolha das famílias beneficiadas para comercialização dos produtos no MPR, constatou-se que $100 \%$ parte do interesse do produtor, além deste obrigatoriamente atender as normativas da vigilância sanitária.

Observa-se na Tabela 1, a relação do número de famílias beneficiadas pelo Programa. Os dados revelam que a maior parcela de famílias beneficiadas por município, gira em torno de 5 a 15 famílias. Considerando-se a base da economia local, que é alicerçada na agricultura familiar, podese considerar que o número de famílias beneficiadas é pequena. A justificativa para essa baixa adesão, de acordo com as falas dos Secretários da Agricultura e o Administrador do Programa, é o fornecimento de alimentos por parte dos produtores ao Programa Nacional de Alimentação Escolar 
(PNAE), e este "ser mais atrativo", em diversos aspectos, como valores pagos aos produtos, regularidade no fornecimento, planejamento de demanda e potencialidades de crescimento.

Tabela 1 - Número de famílias beneficiadas por município pelo Programa MPR

\begin{tabular}{lc}
\hline Número de famílias beneficiadas & f \% \\
Até 5 famílias & 16,67 \\
De 5 até 10 famílias & 33,34 \\
De 10 até 15 famílias & 33,34 \\
Mais de 15 famílias & 16,67 \\
\hline Total & 100 \\
\hline
\end{tabular}

As relações de trabalho dos gestores do Programa nos municípios, em sua maioria exercem a função como contratados temporariamente e, apenas uma parcela muito pequena é servidor efetivo comissionado, fato que também não garante a permanecia na gestão do Programa, pois, observa-se que, muito provavelmente o responsável deixará a gestão do Programa num curto espaço de tempo, pois a troca da gestão majoritária no município a cada 4 anos, afeta a continuidade dos trabalhos, o que dificulta o acompanhamento e monitoramento das ações ao longo do ciclo de vida do Programa. Fato que se confirma ao revelar o tempo de atuação na função, que fica entre 2 a 4 anos. Ao encontro com essa questão, aponta-se a capacitação do gestor do Programa. Constatou-se entre os gestores, que nem todos se sentem capacitados para gerenciar o programa. Esse levantamento revela um dado inquietante, pois, ao se tratar de gerenciamento de Programa, PMI (2014), ressalta a importância das habilidades e diferentes conhecimentos por parte dos membros da equipe para elaboração de um planejamento mais detalhado das ações rotineiras, e a capacidade de envolver pessoas ou organizações para a execução destas.

Associado a esses fatores, revela-se ainda que as atendentes de Boxes, responsáveis pela comercialização dos produtos e, também a divulgação do município e suas potencialidades, já que se trata de MPR, são contratadas, e na grande maioria é indicação política partidária. No relato dos entrevistados, fica evidenciada a presença de indicação política partidária para o preenchimento dessas vagas, além de afirmarem que não é exigida ou proporcionada qualificação para o exercício da função, mesmo que a consideram importantes, porém, não souberam responder o motivo pela não capacitação.

\subsection{Gestão do Programa MPR}

A gestão de qualquer Programa é importante para as organizações, neste sentido buscou-se avaliar a condução dos trabalhos, tanto pelos municípios como pelo CIDEMA na percepção dos gestores do Programa. Apresentam-se os dados sobre a condução dos trabalhos na Tabela 2. Ao abordar a questão da gestão compartilhada, e se está atende as expectativas, obteve-se $100 \%$ de concordância, sendo que $50 \%$ parcialmente e $50 \%$ totalmente. No que se refere a questão de melhorias necessárias para fomentar o programa diante de demandas indicadas pela gestão, percebe-se uma divergência muito forte entre opiniões, pois, apenas $16,67 \%$ concordam totalmente com tal afirmativa, enquanto que 33,34\% concordam parcialmente, 33,34\% são indiferentes e $16,67 \%$ discordam parcialmente da afirmativa. Ressalta-se que na entrevista de forma unanime, transpareceu na fala que, nem sempre ocorrem as melhorias propostas, pois estes relatam que são diversos os entraves, que vão desde "orçamento e vontade política".

Quanto a existência de uma rede de integração (logística) de coleta e transporte dos produtos até o MPR, observa-se unanime entre os respondentes, afirmam não existir uma rede de integração logística para a coleta e transporte dos produtos até o MPR. Fato que pode ser considerado como algo que encarece e torna menos atrativo o Programa para as partes interessadas, corrobora a fala do administrador do Programa, quando afirma que, "a distância dos municípios do MPR, é um entrave, 
pois é inviável trazer produtos que ficam num raio de $100 \mathrm{~km}$ de distância, isso encarece o produto para o consumidor final". O que é confirmado pela fala do Secretário da Agricultura "saímos do município com veículos oficiais para deslocar os produtos". Em relação ao registro e partilha das experiências de gestão do Programa, observa-se ser deficitária, pois, 50\% afirma não existir essa prática, $16,67 \%$ ficaram indiferentes, $33,34 \%$ dizem existir essa partilha, porém 16,67\% de forma parcial e apenas $16,67 \%$ totalmente.

Em relação à capacitação oferecida pelo CIDEMA aos gestores do Programa e, as expectativas dos municípios nessa gestão, observa-se um nível considerado de discordância, o que deixa transparecer uma lacuna em relação ao papel do CIDEMA, fato que é reforçado pelas falas dos entrevistados, já que cabe a este como parte interessada e administrador do Programa, a responsabilidade pela orientação dos trabalhos, o que contempla a capacitação da gestão de todos os municípios associados. De acordo com PMI (2014), os gerentes de programas gerenciam a equipe e também proporcionam a visão e liderança global do Programa. Na questão que trata do registro dos conflitos entre fornecedores e municípios, como forma de aprendizado, constatou-se que 83,34\% dos municípios não têm essa prática, e os demais são indiferentes quanto essa questão. PMI (2014), afirma que os registros são fundamentais, e que estes fomentam e fortalecem lições aprendidas, que por sua vez, promovem a retroalimentação para o gerenciamento de projetos futuros.

Tabela 2 - Gestão do Programa MPR

\begin{tabular}{|c|c|c|c|c|c|}
\hline \multirow{2}{*}{ Gestão do Programa MPR } & \multicolumn{5}{|c|}{ Nível de Concordância } \\
\hline & 1 & 2 & 3 & 4 & 5 \\
\hline $\begin{array}{l}\text { As expectativas do Programa são atendidas pela gestão } \\
\text { compartilhada (CIDEMA e MUNICÍPIO) }\end{array}$ & & & & $50,00 \%$ & $50,00 \%$ \\
\hline $\begin{array}{l}\text { As melhorias necessárias para fomentar o programa são } \\
\text { realizadas conforme demanda indicada pelos gestores. }\end{array}$ & & $16,67 \%$ & $33,34 \%$ & $33,34 \%$ & $16,67 \%$ \\
\hline $\begin{array}{l}\text { Existe uma rede de integração entre os municípios para a } \\
\text { coleta e transporte dos alimentos até o mercado público. }\end{array}$ & $100,00 \%$ & & & & \\
\hline $\begin{array}{l}\text { Os municípios registram e partilham experiências de gestão } \\
\text { do programa com os demais municípios parceiros. }\end{array}$ & $50,00 \%$ & & $16,67 \%$ & $16,67 \%$ & $16,67 \%$ \\
\hline $\begin{array}{l}\text { A capacitação oferecida pelo CIDEMA para a gestão do } \\
\text { Programa no município é efetiva. }\end{array}$ & $16,67 \%$ & $33,34 \%$ & & $16,67 \%$ & $33,34 \%$ \\
\hline $\begin{array}{l}\text { Os conflitos entre os fornecedores do Programa e municípios } \\
\text { são registrados, buscando aprendizado para solução de futuros } \\
\text { problemas. }\end{array}$ & $33,34 \%$ & $50,00 \%$ & $16,67 \%$ & & \\
\hline $\begin{array}{l}\text { A gestão do Programa no município é responsabilidade de } \\
\text { uma equipe. }\end{array}$ & $16,67 \%$ & & & $50,00 \%$ & $33,34 \%$ \\
\hline $\begin{array}{l}\text { A gestão do Mercado Público Regional pelo CIDEMA } \\
\text { atende as expectativas e requisitos dos municípios. }\end{array}$ & $33,34 \%$ & $16,67 \%$ & $16,67 \%$ & & $33,34 \%$ \\
\hline $\begin{array}{l}\text { A produção semanal por família é limitada por uma demanda } \\
\text { mínima de produtos. }\end{array}$ & $33,34 \%$ & $16,67 \%$ & $33,34 \%$ & $16,34 \%$ & \\
\hline $\begin{array}{l}\text { Os produtores são capacitados/orientados para melhorar a sua } \\
\text { produção. }\end{array}$ & $16,67 \%$ & & & $16,67 \%$ & $66,68 \%$ \\
\hline $\begin{array}{l}\text { O foco da produção de produtos é definido por cada } \\
\text { produtor. }\end{array}$ & $16,67 \%$ & & & & $83,45 \%$ \\
\hline
\end{tabular}

Fonte: Elaborado pelos autores (2016).

Ao abordar a questão da gestão em relação à produção e comercialização, fica evidente a falta de organização por parte da gestão, desde municípios e CIDEMA, pois a produção é aleatória, não tendo controle de demanda por produtos, e o foco de produção é definido pelo produtor. Fato destacado nas falas dos entrevistados, pois como a produção rural tem períodos sazonais isso realmente ocorre. A prática sem uma estimativa de demanda acaba gerando um nível considerado de perdas, já que existe uma oferta maior que a demanda, o que causa prejuízo ao produtor rural, e os preços são influenciados pela lei da procura e oferta. 


\subsection{Responsabilidades e influências na gestão do Programam MPR}

Buscando compreender a forma de gestão, bem como as responsabilidades e influências das partes interessadas (municípios) no Programa, apresenta-se os resultados na Tabela 3. Com base nessas informações, pode-se concluir que a gestão ocorre de forma compartilhada, porém, não é unanimidade entre os pesquisados. Já o resultado ao abordar a questão de influências na tomada de decisão, constatou-se que existe uma discrepância entre opiniões, e uma forte abstenção em posicionar-se sobre tal questão. Revela-se, com a fala dos entrevistados, que o fator político tem forte relevância na tomada de decisão.

Tabela 3 - Influências das partes interessadas na Gestão do Programa MPR

\begin{tabular}{|c|c|c|c|c|c|}
\hline \multirow{2}{*}{$\begin{array}{c}\text { Influências das partes interessadas (municípios) na gestão } \\
\text { do Programa. }\end{array}$} & \multicolumn{5}{|c|}{ Nível de Concordância } \\
\hline & 1 & 2 & 3 & 4 & 5 \\
\hline $\begin{array}{l}\text { A gestão do Programa é compartilhada entre os municípios e } \\
\text { CIDEMA. }\end{array}$ & $16,67 \%$ & & & $66,67 \%$ & $16,67 \%$ \\
\hline $\begin{array}{l}\text { Algum município tem maior influência na tomada de decisão } \\
\text { dentro do Programa. }\end{array}$ & $50,00 \%$ & & $33,34 \%$ & $16,67 \%$ & \\
\hline $\begin{array}{l}\text { Ocorrem reuniões para encaminhamentos com todos os } \\
\text { municípios integrantes do Programa. }\end{array}$ & & & & $50,00 \%$ & $50,00 \%$ \\
\hline $\begin{array}{l}\text { As decisões tomadas no Programa fortalecem a organização e } \\
\text { condução dos trabalhos nos municípios. }\end{array}$ & & & $33,34 \%$ & $33,34 \%$ & $33,34 \%$ \\
\hline $\begin{array}{l}\text { A responsabilidade das decisões no que se refere ao } \\
\text { cadastramento dos beneficiários/famílias produtoras é de } \\
\text { responsabilidade do município. }\end{array}$ & $33,34 \%$ & & $16,67 \%$ & $16,67 \%$ & $33,34 \%$ \\
\hline $\begin{array}{l}\text { O CIDEMA estabelece regras e informa os municípios } \\
\text { quanto ao processo de comercialização dos produtos no } \\
\text { Mercado Público Regional. }\end{array}$ & $16,67 \%$ & & & $50,00 \%$ & $33,34 \%$ \\
\hline $\begin{array}{l}\text { O monitoramento e controle da comercialização dos produtos } \\
\text { no Mercado Público Regional são realizados pelo CIDEMA. }\end{array}$ & $16,67 \%$ & $16,67 \%$ & & $33,34 \%$ & $33,34 \%$ \\
\hline $\begin{array}{l}\text { A divulgação do Mercado Público é de responsabilidade } \\
\text { conjunta. }\end{array}$ & $33,34 \%$ & & & $33,34 \%$ & $33,34 \%$ \\
\hline A Gestão do Programa poderia ser mais ativa. & & & $16,67 \%$ & $16,67 \%$ & $66,67 \%$ \\
\hline $\begin{array}{l}\text { O CIDEMA juntamente com os municípios fomenta algum } \\
\text { programa de apoio financeiro para melhorar ou ampliar a } \\
\text { estrutura "física" dos produtores. }\end{array}$ & $33,34 \%$ & & $16,67 \%$ & $16,67 \%$ & $33,34 \%$ \\
\hline $\begin{array}{l}\text { Os produtores recebem assistência técnica para inovar e } \\
\text { diversificar os produtos. }\end{array}$ & $16,67 \%$ & & $33,34 \%$ & $50,00 \%$ & \\
\hline $\begin{array}{l}\text { Os produtos a serem comercializados no Mercado Público } \\
\text { Regional são definidos pelo município, após um estudo de } \\
\text { potencialidade local. }\end{array}$ & $16,67 \%$ & & $33,34 \%$ & $50,00 \%$ & \\
\hline
\end{tabular}

Fonte: Elaborado pelos autores (2016).

Quanto a questão de reuniões e encaminhamentos de todas as partes interessadas, e se as tomadas de decisão no Programa fortalecem a organização e condução dos trabalhos, observa-se um nível considerado de concordância. PMI (2014), corrobora, relaciona o engajamento das partes interessadas, com o compromisso continuado, a gestão das expectativas, negociando e comunicando para almejar as metas do projeto, identificar pontos críticos do projeto com antecedência, solucionar os conflitos e potencializar o sucesso.

$\mathrm{Na}$ questão da responsabilidade do cadastramento das famílias serem do município, obtevese um nível elevado de divergência entre as ações, expondo a falta de entendimento das responsabilidades por parte dos municípios. Observa-se também, que o CIDEMA, estabelece regras em relação à comercialização dos produtos, e as informa aos municípios, porém, quanto ao monitoramento e controle da comercialização dos produtos, não existe essa clareza por parte de todos os municípios pesquisados. Outro fator que vem ao encontro dessa constatação, é que os municípios pesquisados, concordam que a gestão do Programa poderia ser mais ativa. Nessa 
perspectiva, PMI (2014) relaciona o sucesso do Programa, pelo grau em que o programa atende às necessidades e pelos benefícios para os quais foi executado.

No aspecto da assistência técnica proporcionada aos produtores para a diversificação da produção, verificou-se que existe divergência nos resultados, em alguns municípios ela ocorre, no entanto, nos demais essa prática não ocorre. Por outro lado, cabe aqui destacar a fala dos entrevistados, que consiste numa assistência precária, haja vista que não tem um estudo de potencialidades para novos produtos, o que se comprova nos dados apresentados, pois nenhum município fez um estudo das potencialidades, dificultando a assistência direcionada para diversificação.

Quanto ao fomento aos produtores com auxílio financeiro para diversificação e ampliação da estrutura física, remete a divergências significativas na opinião do pesquisados, o que se confirma também no que tange a divulgação do Programa. Atribui-se a isso a falta de clareza das responsabilidades por parte das partes interessadas, e também das ações do Programa. De acordo com PMI (2014), planejar o gerenciamento das partes interessadas é a técnica de aprimorar as estratégias, envolvê-las de maneira eficaz ao longo do ciclo de vida, atender as necessidades, interesses e o potencial do projeto. Sugere também, reuniões com especialistas, as quais permitem identificar o nível de engajamento das partes interessadas, confrontando o planejado com o esperado, identificando eventuais lacunas para ajustes necessários.

\subsection{Identificação do município com o Programa MPR}

A Tabela 4 apresenta e sintetiza a resposta das partes interessadas quanto à identificação do município com o Programa MPR. Observa-se num primeiro momento, o Programa não proporciona visibilidade a todos os municípios na região, pois ocorre uma discrepância muito forte entre opiniões. Quando questionados, se o Programa fortalece o município no desenvolvimento e fortalecimento da agricultura familiar, identificou-se que nem em todos os municípios ocorre esse fortalecimento. Outra questão que corrobora com tal afirmativa, são as constatações ao questionar se o Programa beneficia as famílias no âmbito econômico e social, pois 33, 34\% dos respondentes ficaram neutros, $33,34 \%$ concordam parcialmente e apenas os demais concordam totalmente.

Tabela 4 - Identificação do município com o Programa MPR

\begin{tabular}{|l|c|c|c|c|c|}
\hline \multirow{2}{*}{ Identificação do município com o Programa } & \multicolumn{5}{|c|}{ Nível de Concordância } \\
\cline { 2 - 5 } & $\mathbf{1}$ & $\mathbf{2}$ & $\mathbf{3}$ & $\mathbf{4}$ & $\mathbf{5}$ \\
\hline $\begin{array}{l}\text { O Programa proporcionou maior visibilidade ao município } \\
\text { na região. }\end{array}$ & $16,67 \%$ & $16,67 \%$ & $16,67 \%$ & $16,67 \%$ & $33,34 \%$ \\
\hline $\begin{array}{l}\text { O programa fortalece o município no desenvolvimento e } \\
\text { fortalecimento da agricultura familiar. }\end{array}$ & $33,34 \%$ & $16,67 \%$ & $33,34 \%$ & $16,67 \%$ \\
\hline $\begin{array}{l}\text { O Programa beneficia as famílias produtoras no âmbito } \\
\text { econômico e social. }\end{array}$ & & $33,34 \%$ & $33,34 \%$ & $33,34 \%$ \\
\hline $\begin{array}{l}\text { Ocorre ampla divulgação do Programa no município e } \\
\text { região. }\end{array}$ & $33,34 \%$ & $16,67 \%$ & $16,67 \%$ & $16,67 \%$ & $16,67 \%$ \\
\hline $\begin{array}{l}\text { O investimento realizado pelo município no Programa } \\
\text { atendem as expectativas de retorno }\end{array}$ & $33,34 \%$ & $33,34 \%$ & & $16,67 \%$ & $16,67 \%$ \\
\hline Há interesse das famílias em participar do programa. & $16,67 \%$ & $16,67 \%$ & & $33,34 \%$ & $33,34 \%$ \\
\hline $\begin{array}{l}\text { O Programa fortalece vínculos com a agricultura familiar e } \\
\text { proporciona aumento de renda para as famílias do programa. }\end{array}$ & $16,67 \%$ & & $16,67 \%$ & $50,00 \%$ & $16,67 \%$ \\
\hline
\end{tabular}

Fonte: Elaborado pelos autores (2016).

Em relação ao conhecimento dos munícipes sobre o Programa e seus benefícios, bem como a divulgação deste observa-se uma discrepância entre as respostas, pois enquanto que 66,68\% não concordam ou se abstiveram em responder, sobre a divulgação, outros 66,68\% afirmam que os munícipes conhecem o Programa e seus benefícios. 
Quanto ao interesse das famílias em participar do Programa, temos um nível de concordância de $66,67 \%$, no entanto, ao confrontar este dado com o número de famílias beneficiadas pelo Programa, observa-se que o número de famílias beneficiadas por município é na média de 5 a 10 famílias, o que caracteriza uma proporção não muito significativa, se considerarmos o número total de famílias agricultoras, que gira na média de 450 famílias por município. Na mesma lógica, esta o aumento de renda para as famílias, pois, temos um número significativo que afirma não ocorrer esse aumento, ou mantiveram-se neutros na resposta, e 50\% concordam parcialmente com tal afirmativa.

Outra constatação é a falta de monitoramento de forma efetiva por parte do município, em relação à produção por família, fato que reflete na análise dos investimentos realizados pelo município, pois o resultado apresenta um alto índice de discordância, ou seja, afirmam que o investimento realizado não atende as expectativas de retorno. Fato esse que se confirmou na fala dos entrevistados, no entanto, também destacaram que, não somente aspectos econômicos são considerados na área pública, e que os aspectos sociais são maiores que o lucro, e que o objetivo principal não visa lucro, e sim a qualidade de vida das famílias, evitando assim, o êxodo rural e o aumento das mazelas sociais na cidade. De acordo com Carvalho (2012), as esferas públicas, nem sempre compartilham os mesmos objetivos e, menos ainda, concordam com a forma de gestão para atingi-los.

\section{CONCLUSÃO}

A prática do gerenciamento de projetos vem adquirindo notoriedade no cenário das organizações, como ferramenta gerencial é o elo na aplicação de conhecimentos, habilidades e técnicas para atender as demandas de um ambiente cada vez mais dinâmico e exigente, sendo que, neste processo, o gerenciamento das partes interessadas ganha destaque. Neste contexto, a presente pesquisa partiu do objetivo de analisar o gerenciamento do Programa MPR a partir da percepção das partes interessadas (municípios e CIDEMA).

Quanto ao mapeamento das partes interessadas (municípios) do Programa MPR, levantou-se que ao iniciar as atividades em 2007, contava com 10 municípios, e atualmente 7 municípios mantém o contrato de rateio com o CIDEMA, entretanto, no momento, apenas 5 municípios estão com atividades de comercialização, os demais tem o espaço, porém estão fechados, ou por demanda ou questões administrativas. O número de famílias fornecedoras é pequeno, considerando a base da econômica dos municípios, a agricultura familiar, pois o objetivo principal do Programa MPR é o fortalecimento da agricultura familiar e a sustentabilidade dos municípios.

Observou-se também que, a presença do fator político é um obstáculo no avanço da gestão do Programa, pois, revelou-se que os responsáveis pela gestão nos municípios e CIDEMA, bem como os atendentes dos Box, são oriundos de indicação político, e este associados ao pleito eleitoral municipal, revela a troca de gestão de forma abrupta, e nem sempre a continuidade dos trabalhos na próxima gestão. Fato que se agrava, ao constatar não existir um levantamento de potencialidades, o registro e partilha das lições aprendidas, e tampouco, o monitoramento das ações, que na sua grande maioria, sequer foram planejadas.

No que se refere à gestão do Programa entre CIDEMA e municípios, percebeu-se que não existe um planejamento definido das ações, cada qual segue sua própria metodologia, não há clareza sobre as atribuições e responsabilidades em relação ao Programa como um todo, nem tampouco o que é de atribuição dos municípios e do administrador para prospectar e fomentar o Programa. Destaca-se que em empreendimentos públicos, nem sempre se compartilha os mesmos objetivos, 
tampouco a forma de geri-los, isso fica evidenciado na pesquisa no momento que os dados divergem.

Quanto à gestão de conflitos entre as partes interessadas, avalia-se que o Programa não gera uma atividade intensa, consequentemente, não cria uma perspectiva de crescimento e fortalecimento do município num contexto regional, acaba esta por ser mais uma atividade no rol de prestação de serviços instituída por vontade política, onde nenhuma pessoa se habilita a contestar o funcionamento do Programa. Nas entrelinhas, deixam transparecer que o Programa, é um "fardo" aos municípios, pois não se criou uma identidade do Programa MPR com as características iniciais de sua fundação, pelo fato da distancia entre polo consumidor e fornecedor.

Já em relação às influências das partes interessadas na gestão, avalia-se existir uma tendência significativa, ou seja, alguns atores têm grau de poder e influência maior, o que dificulta o engajamento das partes interessadas, já que o que legitima esse poder e influência é a questão política partidária, aumentando os desencontros ao longo do processo, além de gerar resistência. Esse impacto é avaliado como negativo para o Programa, pois as diretrizes de gestão da esfera pública preconizam por uma gestão equânime dos recursos públicos, bem como, seus respectivos benefícios à população.

Quanto à identificação dos municípios com o Programa, avaliou-se que o Programa tem uma carência latente nos aspectos de planejamento das ações, sua real necessidade de fomento e existência, indicadores para o monitoramento e controle, envolvendo aspectos de produção, número de famílias atendidas, demandas por produtos específicos de cada município, levantamento de potencialidades locais e regionais que possam justificar o investimento realizado pelos municípios no Programa MPR.

Portanto, com base na pesquisa realizada pode-se concluir que a forma de gestão do Programa MPR não é eficaz, efetiva e nem tampouco eficiente. Não basta de boa vontade, precisase de uma gestão respaldada num planejamento condizente, com dados que possam contribuir para implementar melhorias e prospectar o MPR a nível local e regional, fortalecendo a agricultura familiar e consequentemente fomentando a sustentabilidade dos municípios da região. No que se refere às partes interessadas, demonstra-se a deficiência em torná-las engajadas ao processo, pode se atribuir tal situação, ao fato do não conhecimento da real finalidade do programa, a falta de capacitação para gerenciar o que lhe compete, a falta de recursos financeiros, a falta de comunicação, a falta de identificar pontos críticos, a falta de gerir expectativas, e, o controle e monitoramento, tudo o que fomenta as ações para documentar as lições aprendidas e retroalimentar o processo.

Quanto às sugestões de melhoria pode-se indicar: uma rota de integração para coleta dos produtos, realizar pesquisa local das potencialidades, desde a produção da agricultura e as peculiaridades do município, promover um rodízio entre os dias da semana com produtos distintos e caracterizados por município, capacitar gestores e atendentes, registrar e partilhar experiências mensalmente entre gestores e atendentes, monitorar a produção e comercialização, levantar demandas potenciais, qualificar produtores e a divulgação do MPR nas mídias sociais. Sugere-se para trabalho futuro, a análise da relação das partes interessadas, envolvendo, agricultores, consumidores e atendente do Box, além da integração do MPR com o fornecimento de alimentos ao PNAE e suas potencialidades. 


\section{REFERÊNCIAS}

BRASIL. Tribunal de Contas da União. Manual de gestão de projetos. Brasília: TCU, 2006.

BRASIL. Secretaria de Estado de Planejamento e Gestão. Subsecretaria de Planejamento - SUBPL. Manual de Elaboração do Plano Plurianual 2012 - 2015. Rio de Janeiro, 2011.

CARVAlho, C. J. Elaboração e Gestão de Projetos. 2. ed. reimp. -Florianópolis: Departamento de Ciências da Administração/UFSC; [Brasília]: CAPES: UAB, 2012.

DEMO, P. Metodologia do conhecimento cientifico. São Paulo: Atlas. 2000.

FERRARI, A.T. Metodologia da pesquisa cientifica. São Paulo: McGraw-Hill do Brasil, 1982.

GIL, A.C. Como elaborar projetos de pesquisa. 4. ed. São Paulo: Atlas, 2002.

KEELLING, R.; BRANCO, R.H.F. Gestão de Projetos - uma abordagem global. São Paulo: Saraiva. $3^{\text {a }}$ Ed. 2014

KEELING, R. Gestão de projetos: uma abordagem global. São Paulo: Saraiva, 2002.

NORO, G. de B. A gestão de stakeholders em gestão de projetos. Revista de Gestão de Projetos. São Paulo. v.3,n.1.p 127-158. Jan./abr. 2012.

MAXIMIANO, A.C.A. Administração de projetos: como transformar ideias em resultados. 4. ed. - São Paulo: Atlas, 2010.

RICHARDSON, R. J. Pesquisa social: métodos e técnicas. 3. ed. São Paulo: atlas, 2012.

PMI - Project Management Institut. Guia do Conhecimento Em Gerenciamento de Projetos - Guia Pmbok® - $5^{\text {a }}$ Ed. 2014.

TRENTIM, M. H. Stakeholders como clientes nos projetos. Revista Mundo Project. Curitiba. Ano 8. $\mathrm{n}^{\circ}$ 49, p,??. Fev/Mar. 2013.

SILVA, W. C.;ROCHA E MUCCI, C.B.M.;BAETA,O.V.; ARAÚJO, D.S. O Planejamento estratégico na administração pública: um estudo muLticaso. Revista de C. Humanas. Viçosa, v.13, nº.I,p. 90-101,jan/jun. 2013.

VALLE, A.B. do.; CIERCO, A.A.; SOARES, C.A.P.;FINOCCHINHO JUNIOR, J. Fundamentos do gerenciamento de projetos. 3. ed.- Rio de Janeiro: FGV, 2014.

VARGAS, R.V. Gerenciamento de projetos: estabelecendo diferenciais competitivos. 7. ed. Rio de Janeiro: Brasport, 2009.

VERGARA, S.C. Projetos e relatórios de pesquisa em administração. 3. ed. São Paulo: Atlas, 2000. 